\title{
Mobility Intersections: Social Research, Social Futures
}

\author{
MONIKA BÜSCHER ${ }^{1}$, MIMI SHELLER ${ }^{2}$, DAVID TYFIELD ${ }^{1}$ \\ ${ }^{1}$ Centre for Mobilities Research, Lancaster University, Lancaster, UK \\ ${ }^{2}$ Department of Sociology, Center for Mobility Research and Policy, College of Arts and \\ Sciences, Drexel University, Philadelphia, PA, USA
}

\begin{abstract}
This special issue seeks to deepen conversations at the intersections between mobilities research and a number of adjacent fields. Contributions explore how mobilities research has emerged and travelled along with a range of approaches concerned with the lived production of socio-material orders, such as science and technology studies, non-representational and feminist theory, critical and speculative design, and cosmopolitanism, to name but a few, while also intersecting with many applied fields, such as transport planning and policy, disability studies, or disaster response. The field of mobilities research has grown by connecting different epistemological frames, and offering new post-disciplinary approaches to complex interconnected phenomena. In pausing to reflect on these mobility intersections, we suggest that mobilities research is integral to a broader project of transforming the social sciences that is currently underway
\end{abstract}

\section{Intersections}

Mobilities research has become a hub of analytical insight for a diverse and expanding range of different parties, whether academic, applied, or creative. Academic disciplines spanning the social sciences, the arts and humanities, and media and communication have gathered around the momentum of mobilities research, and professional fields including medicine, law, social work, architecture and engineering have found sources of inspiration. Practitioners in design, creative arts, transportation research and planning, urban planning and policy find actionable understanding in mobilities studies, in no small part because inquiries into the dynamics of movement and stasis cross many boundaries and address many phenomena, sometimes surprising. The field of mobilities research has grown by connecting different epistemological frames, and offering new post-disciplinary approaches to complex interconnected phenomena. Today we see several of the phenomena that inspired it coming to a head. Existing mobility systems are peaking (peak car, peak oil), transforming (publicprivate, climate), transitioning (new technologies, surveillance) and emerging (global 
disasters, planetary mobilities) (Urry 2011, 2013; Metz 2013; Geels et al. 2013; Sheller and Urry 2003, Szerszynski, this issue). ${ }^{1}$

Mobilities research has thus fundamentally challenged and changed social science (Sheller and Urry 2016). But as it has grown, the concept of 'mobilities' has become broader (and it started as a broad concept!) and its ambitions have stretched. Some argue that we need clearer conceptual definition, since "if mobility is everything then it is nothing" (Adey 2006). Others suggest that we now need to put concerted effort into defining alternative mobility futures as social futures and more effective ways of shaping them (Dennis and Urry 2009, Bonham and Johnson 2015, Urry 2016). This lends a certain urgency to the need to reflect on the current status of the field and creates a need for critical reflection about where mobilities research is now (see Faulconbridge \& Hui 2016) and where it may, or should, move towards. This special issue therefore seeks to deepen conversations at the intersections between mobilities research and a number of fellow analytical orientations, competing frameworks and adjacent fields. We take "intersection" to mean both a crossroads of research programmes moving in multiple directions that cross spatially to form a productive and sometimes provocative meeting point, and as an intersectional temporal process or ongoing course of action, such as the performative intersectionality of multiple overlapping and interdependent identities and emergent orientations.

By nature, such reflection has to be a broad-based and collective, trans-disciplinary and multi-dimensional undertaking. Mobilities research has emerged and travelled along with a range of approaches concerned with the lived production of socio-material orders, such as science and technology studies, non-representational and feminist theory, media and cultural studies, ethnomethodology, critical and speculative design, and cosmopolitanism, to name but a few. It has covered many empirical phenomena of mobility, immobility, blocked and coerced movement, mobility systems and infrastructures. Its foci range from walking to automobility, aeromobility, cycling and vélomobility (Middleton 2010; Dennis and Urry 2009; Kaplan 2006; Cwerner et al. 2009; Adey 2010, Furness 2007, Aldred and Jungnickel 2014, Spinney 2016) to the (im)mobilities of borders (Amoore 2006; Adey 2009; Vukov and Sheller 2013) and the complexities of offshoring (Urry 2014). For mobilities scholars, the intersections between these divergent approaches and seemingly scattered phenomena do not create a non-place, to be moved through quickly with a decisive sense of direction. They are places, an entrepôt ( $C f$ Braudel 1982), for dwelling in diversity, encounter, conflicting perspectives and negotiation; or a "strange attractor" (Urry 2003) in which to seek connection, reflection, friction, a place to return to though it is never the same. 'Intersections' - of routes, perspectives, ways and (biographical) journeys - are thus places in which to meet for a time before taking fresh departure.

With these generative intersections and potential futures of mobilities and mobilities research in mind, we organized a workshop at Lancaster University in July 2015 in which we asked contributors representing a wide range of fields and disciplinary orientations to explore a set of key questions from different perspectives, including:

- What kinds of mobilities shape humanity's futures?

- What are the key social, ethical, political issues that relate to mobility?

- What kinds of futures should mobilities-oriented social research generate?

\footnotetext{
${ }^{1}$ Henceforth, where no date is given in a citation, it refers to a paper in this Special Issue. Papers in this issue are listed as such on their first citation.
} 
- How does and how should mobilities research, in intersection with other analytical approaches, move futures into view?

- How does and how should this encounter enable responsible future-shaping?

More specifically, out of the workshop it emerged that 'Intersections' connotes three key ideas that we investigate in this special issue, and in this introduction:

First this special issue explores overlapping and cross-cutting fields, which we investigate in terms of the interconnections between the mobilities paradigm and 'adjacent' approaches. It showcases pioneering theoretical developments/syntheses between mobilities research and a diverse range of adjacent theoretical perspectives. Relevant fields include: science and technology studies and non-representational theory (Barad 2007; Thrift 2007); theories of risk and cosmopolitanism (Beck 2006; Beck et al. 2013; Tyfield and Blok, this issue); securitization (Packer 2008; Adey 2009; Anderson 2010; Aradau 2004, and this issue; Amoore 2006); transition theory (Geels 2002; Geels et al. 2013; Kanger and Schot, this issue; Sheller 2011; Tyfield 2014); disability studies (Sawchuk 2014; Parent, this issue; Goggin, this issue); urban studies (Hall and Smith 2015 and this issue; Middleton 2010; Brenner and Schmid 2015); design research (Galloway et al. 2004, Ehn 2008, Simonsen et al. 2010, Kimbell 2011, Jensen 2013, 2014, and this issue); feminist theories of space and gendered mobilities (Kaplan 1996; Massey 1994; McDowell 2013; Murray et al., this issue). How can intersections, syntheses, and frictions between mobilities research and these adjacent theoretical perspectives (and others besides) lead to deeper and more useful insights into contemporary forms of life that inform theoretical, methodological, epistemological and critical, creative future-making moves in the social sciences and beyond?

Secondly, we consider more specifically the 'intersectionality' so important to contemporary inequalities by way of differential (im)mobilities and uneven mobilities at multiple scales (Sheller 2016a). We chart important emergent issue areas, such as data flows and their (im)mobilities; or the gendered, racialised, and differentially embodied (im)mobilities of inequality; the making of 'good mobilities' and 'good cities'; or the uneven mobilities of disaster vulnerability and climate adaptation. Here the mobilities paradigm intersects especially with disability studies (Parent 2013; Sawchuk 2014; Parent, this issue; Goggin, this issue); gender studies, critical race theory, and intersectional spatial formations of age, race, class, and sexuality (Cresswell 2006, 2016; Sheller 2015; Nicholson and Sheller 2016; Nicholson, this issue; Murray et al., this issue); cultural theory, feminist cultural theory and research creation (Goggin 2011, Chapman and Sawchuk 2012); and the multiple publics who are unequally involved in shaping futures in areas such as humanitarian response and crisis informatics (Palen et al 2009; Büscher et al 2014; Sheller 2013, 2016b).

Thirdly, the contributions in this special issue also explore intersections as spaces or points of many paths, hence also as moments of discovery, the opening up of new perspectives, of friction, and new analytical traction, but also disorientation, (re-)definition of purpose, searching for (re-)orientation, exchange and shared journeys; in the objects of our study, in how and why we study them, and in how we bring insight into action. Seemingly all around us are accelerating mobilities, system breakdown/crisis and uncertain and embryonic emergence of new systemic mobility constellations. Mobilities research explores how the social world is constituted of complex adaptive systems stretching over time-space. In drawing on complexity theory joined with transitions theory and social practice theory, the new mobilities paradigm disrupts existing disciplinary boundaries and reorients 'normal' social science, leading to new communities of practice, new kinds of applied research, as well 
as new scales for social theory (Sheller and Urry 2016). Mobile methods can complement and extend social research methodologies (Merriman 2013), and provide novel traction for analysis, re-configuration and invention at different scales, from the intimacies of urban walking or wheeling to the complexities of offshoring (Fincham, McGuinness and Murray 2009, Büscher, Urry and Witchger 2011).

Mobilities research is integral to a broader project of transforming the social sciences that is currently underway - of which public, inventive, co-creative and 'phronetic' or practically oriented 'prudent' forms of social science are other key examples (Burawoy 2005, Lury and Wakeford 2012, Hartswood et al 2002, Chapman and Sawchuk 2012, Flyvbjerg et al. 2013; Tyfield and Blok, this issue). Multiple points of convergence between mobilities research, engaged citizenship, science, technology, social science and design create opportunities and challenges for new ways of defining and doing responsible research and innovation (Owen, Macnaghten and Stilgoe 2012). How does and how should mobilities research dwell in intersections to best shape shape the momentum of these efforts (and social science more generally)?

With the $10^{\text {th }}$ anniversary of the mobilities paradigm as milestone, this is a timely opportunity to inquire about the next ten years. In a present that is a specific, and perhaps historically unprecedented, condition of mobile complexity - of so-called 'knowledge' and hi-tech societies confronted with multiple, proliferating, un-knowable and interacting complex systems - what mobility futures are taking shape? In short, we are in a predicament demanding both the development of new knowledges of extra-ordinary ambition and admissions of inescapable ignorance and epistemic limitation; a predicament that is, in itself, intolerably paradoxical and paralyzing for familiar 'modern' definitions of scientific knowledge. Perhaps the first thing needed, therefore, is to stop and open oneself up for surprises (Gross 2010).

\section{Dwelling in Intersections}

Intersections are openings where paths cross, and questions of intersectionality and purpose together resonate with the sense that the present is a moment of enormous social challenges, which centrally feature 'mobilities' and to which mobilities research must aspire to respond. But such responding may be less a matter of finding answers or 'solutions' than questions and methods that are responsive to the multiplicities and complexities revealed in intersection; indeed, as a critique of 'solutionism' (Morozov 2013). Insofar as there is widespread popular ontological anxiety - regarding the 'march of the robots' and no-job futures or even human redundancy, climate change, planetary boundaries and geoengineering technical fixes, or ubiquitous threats of terrorism and/or total surveillance - then these concerns about knowledge/power technological change demand that some foundational categories and dualisms of the modern age and its episteme are problematized.

Here are some of the questions of epistemology, method, and debates about the relationship between knowledge, design, and action that animated our workshop: Can ethnomethodology (Laurier 2004; Büscher 2006, Hall and Smith this issue), in intersection with design (Hartswood et al 2002; Jensen this issue) address some of these anxieties? Can mobilities theory and mobile methods (Sheller and Urry 2006; Kesselring 2006; Fincham, McGuinness and Murray 2009; Büscher, Urry and Witchger 2011) create new forms of knowledge and social action? Are there more inventive "vital" and moving methods (Lury and Wakeford 2012; Sheller 2014, Büscher 2016), forms of mobilities design (Jensen 2014, this issue), 
speculative design (Gaver, Dunne and Pacenti 1999; Wilkie and Michael 2009), affirmative critique (Braidotti 2010), design thinking (Kimbell 2011) and critical making (Ratto et al 2014) that can leverage social science more effectively for defining and making 'better' futures? Are there new kinds of mobile publics (Marres 2009; Bruns 2008) that can 'mobilise' citizen social science (Housley et al 2014)?

For some of our contributors, these considerations point toward the seeming emergence of new human (or rather socio-natural) conditions, of 'planetary mobilities' and the Anthropocene (Palsson et al. 2013; Szerszynski 2012, and this issue) and sustainability transitions (Kanger and Schot). Szerszynski notes how growing concern for the impact of human activity, including mobilities, at the level of the system of planet Earth as a whole opens up entirely new and unknown territories of future human understanding and government; a disorientation and ignorance that we are only just coming to acknowledge, let alone address. Kanger and Schot highlight key elements of current ignorance regarding systems, in terms of the current imperative to expedite socio-technical systems transitions towards more ecologically-sustainable models; of which transitions from the current lockedin system of car-based automobility is perhaps the 'hardest case' (Geels et al. 2013: xiii).

Planetary transformations, lock-ins and barriers to transition are rooted in the historical longue durée, and for Aradau (this issue), the very ideas of motion and circulation need to be blurred and reopened, because they shape fundamental dynamics of private/public, self/other, individual/collective subjectivity. Bringing mobilities research into conversation with critical security studies, she examines metaphors of motion, circulation, and mobility in philosophies of governance in 17 th and $18^{\text {th }}$-century Europe. This reveals how concerns with security produced troubled conceptualisations of collective subjectivity as 'the multitude', 'populations' and 'mob' that still thread through contemporary debates. She presents a careful analysis first of Hobbes' way of seeing 'motion as the key to understanding the world'; then, secondly, physiocratic notions of blood circulation embedded in economic ideologies of 'laissez faire, laissez passer', identifying 'blockages' to circulation as a matter for security policies; and, thirdly, the emergence of the idea of 'the mob'. By tracing distinctions between these grammars of motion, circulation and mobility, Aradau leverages novel analytical purchase on contemporary points of intersection between security and mobility such as those found at Calais where the securitisation of migrants' presence is predicated upon boundary work between categories of circulation and mobility even as new spaces and forms of community-making, solidarity and activism open up.

From questions of politics and collective human agency, however, further intersections emerge, regarding the very definition of the 'human' (Harari 2015). Amoore (2015) discusses government (of mobility) by human decision vs. machine algorithm, and how decisions on the direction of this trajectory are already de facto being made, albeit with little or no public debate; raising questions in turn about human 'control' or not of socio-technical novelty, whether as reality or as ideal (see also Jensen, this issue; Nicholson, this issue; Galloway 2015). ${ }^{2}$ Galloway shows how speculative design fictions of digital and non-digital interventions in the conjunction of New Zealand sheep farming and the Internet of Things can foster critical, practical and creative engagement with mobility futures. This also speaks to a new, but as yet unmanageable, responsibility for futures that calls for new epistemic-political technologies and practices of socio-technical innovation that acknowledge issues of

\footnotetext{
${ }^{2}$ Amoore (2015) and Galloway (2015) both contributed to the workshop on Mobility Intersections held at CeMoRe, Lancaster University in July 2015. Unfortunately, for unforeseeable reasons, neither has been able to contribute to this Special Issue. We nonetheless note with gratitude their contribution to its production.
} 
complexity, ignorance and surprise (Gross 2010); a new temporal responsibility all the greater since, combined with the planetary and ecological issues above, it must also strive for long-term futures. Here there are emerging splits between visions of a trans-human future (More and Vita-More 2013), transcending 'mere' humanity with superior machinic intelligence, as against a post-human future of a 'humanity' substantially resituated in both human-human/ human-non-human relations and in its own estimation but not replaced or left behind (Nayar 2014); issues picked up in the context of mobilities and disabilities studies by Goggin (this issue) and Parent (this issue).

In the meantime, mass movements of humans ( $c f$ Aradau) are creating other tense crossroads and mobile intersections, as in the ongoing Syrian "refugee crisis" or more widely a crisis of global apartheid and humanitarianism (Tyler and Loyd 2015), militarized mobilities and new forms of warfare (Kaplan 2006, Gregory 2011) and (contested) prospects of climate refugees (Bettini 2013). Nor are these movements just inter-national and from 'poor' or war-torn to 'rich' worlds. For instance, perhaps no less momentous than global scale displacements are China's internal mass migration and urbanization (see $\mathrm{Xu}$ and $\mathrm{Wu}$, this issue), even as from a Western perspective this is often overlooked; and with similar processes possibly emerging in future in South Asia and Africa. Indeed, changing geopolitical and cultural relations might suggest a global shift from the erstwhile 'core' of a Euro-American-dominated globalization to populous, fast-'developing' and 'mobilizing' countries, of which China is the acme. What does the uncertain but likely global rise of such a fast-changing China mean? Intersecting a mobilities lens into Chinese social and lifestyle studies provides insights into this key question (Xu and $\mathrm{Wu}$ ). Moreover, this is not merely the possible emergence (or resurgence) of a new global 'superpower' but one in the unprecedented context of 'global' and cosmopolitized social realities (Beck 2006).

A further challenge thus presents itself to 'West' and 'East', 'North' and 'South' alike: how will qualitatively new and globally-deployed concepts of the 'global' and 'cosmopolitan' be shaped by and shape, in turn, non-Western cultural resources (Beck \& Grande 2010; Han and Park, 2015; Tyfield and Blok; Xu and Wu). This raises the enticing but daunting challenge to seek new insights and make new connections, not just with a view to momentous social changes in areas often overlooked and inadequately analysed within mobilities research to date, but also to inform analysis through cultural perspectives that, situated at a greater distance from the Euro-American Western paradigm of modern humanism, may prove both productive and difficult. These changing global social relations may offer more positive reorientations, raising questions about how they can be understood, worked with and harnessed to the shaping of brighter, more 'convivial' futures (Tyfield \& Blok), and more circumspect relational ethics (Büscher et al. 2016).

Such considerations, involve acknowledging and wrestling with the limits of method and methodology in the (social) sciences. The wide concerns opening up at the multiple intersections between mobilities research and other perspectives in this special issue show that sociological inquiry is no longer the sole domain of sociology, but of many disciplines from art to computing, history to agricultural biotechnology - as well as outside academia commerce, governance and citizen social scientists (Burawoy 2005; Thrift 2011; Southern 2012; Housley et al 2014) - where it is folded into design, transition, and activism. Mobilities research is driving 'mobile' methods, not just in the sense of moving with research subjects or objects - walk along or wheel-along interviews (Parent) - but also in the sense of 'moving methods', intrinsically implying research co-creation and invention, or intervention; moving 'into' the phenomena under investigation, moving with the human and non-human agents, 
being moved by them and the intended and unintended systemic effects that arise in interaction, and moved to act in relation to values and visions in a move of 'affirmative' critique (Freudendal-Pedersen 2009). This is a form of critique that actively engages in building social research into seeking, defining, shaping and practically making and experimenting with 'better' futures (Freudendal-Pedersen and Kesselring, this issue). The 'affirmative' qualifier does not blunt the teeth of critique. On the contrary, it gives them purchase (or bite!) by 'putting the active back into activism' (Braidotti 2010; Parent; Murray et al.; Tyfield and Blok; Büscher 2016).

Above all, mobility intersections lead to radical re-thinking of how to study emergent social processes, including multiple mobile-cum-immobile socio-technical and socio-natural phenomena. This raises core questions of theory and methodology in terms of what academic research and practice are for, what we do as researchers in the world, and how 'the world' and research participants collaborate in and shape the research and the world (FreudendalPedersen \& Kesselring; Murray et al.; Galloway 2015; Jensen; Nicholson; Tyfield \& Blok). Jensen utilises intersections between mobilities research, actor network theory and design/architecture to explore 'other' materialities (surfaces, voids, volumes etc.) and 'other' ways of looking at materialities. The nuanced sensitivity to materials, spaces, and sensations developed within architecture and design resonates with research into situational mobilities and the mobilities design involved in their unfolding. It makes it possible to take departure in concrete and specific mobile situations and how materialities shape interactions at multiple scales, including large-scale environmental impacts; such as the 'politics of pavements' which explore how their impermeabilty to rain shapes how pavements interact with the dynamics of extreme weather.

Attention to materialities connects the pragmatic question of 'what makes things happen?' across different scales. Tyfield and Blok, in a move that picks up Aradau's concerns with collective subjectivity, situate mobilities research in relation to cosmopolitanization and its potentials for engaging the world in reflexive, learning processes by building bridges across difference. In an exploration of the many different perspectives, motivations and drivers for low-carbon innovation in China, questions - at once eminently practical and abstractly (meta)methodological - arise about epistemic reorientations of methodological cosmopolitanism, an open-ended search for new units of analysis, beyond individual societies and the nation-state, and in search of practical, 'actionable' wisdom. When conceptualized through the lens of such a phronetic and situated research engagement, methodological cosmopolitanism enables enhanced sensitivity to intersectionality, or self-conscious and power-sensitive practices of dialogical intervention in strategic cosmopolitized realities. Recombinations of practice can be productive, as Freudendal-Pedersen and Kesselring show, when they reflect upon how they have used workshops as a mobile methodology. Through carefully curated events that bring together diverse stakeholders and decision-makers to explore urban mobility systems through unbounded, artistic, collaborative exploration that seeks to 'blow minds', they show how it is possible to open up imaginations to find at least the right questions. This is a generative forms of 'staying with the trouble' (Haraway 2010), that leverages the affective and communal aspects of these happenings, which are crucial to their efficacy, as when barriers are dropped and participants find themselves no longer burdened by (self-performed) expectations to be constructive and productive. They can cathartically entertain even dystopic possibilities that open up opportunities for new ways of working with complex mobile systems that practice affirmative forms of critique. 
Moreover, although thinking about what to do in a world riven by exceedingly complex challenges inevitably draws on analogies of movement, where 'ways forward' seem to need to be found, mobilities research has already done much to deconstruct assumptions of linearity and dualisms of mobilities and immobilities that underpin such simplistic ideas of the role of social science, and science as a whole. Perhaps, then, mobilities research can bring new conceptions of 'directions', 'rhythms' and 'movement' regarding the development of knowledge, social life and lived material innovation. The possibility is of new forms and systems with different priorities that grapple with the challenge not of 'moving' (always implicitly 'forward' and/or 'on') but of 'dwelling' or 'living' as relational, involving the work of 'mobilising' or 'imobilising', and of keeping things bounded, bordered, mobile or still.

The papers in this special issue provide deep acknowledgement of the inescapable situatedness within flux in a range of different contexts, drawing on numerous and diverse sources and 'adjacent' disciplines. Like many contemporary social science approaches, they are concerned with the lived practice and production of 'mobility situations' and sociomaterial orders from the microscales of streetscapes to the planetary scales of abiotic, biotic and technological mobilities (Parent, Jensen, Murray et al, Hall and Smith, Szerszynski), they chart important emergent issue areas, such as: violence, disaster and crisis (Aradau, Nicholson); migration (Aradau, Xu and Wu), data flows and their (im)mobilities (Amoore, Galloway); sustainability and transition (Tyfield and Blok, Schot and Kanger, Freudendal and Kesselring) or the gendered, newly racialised, and differently embodied (im)mobilities of inequality (Murray et al, Nicholson, Parent, Goggin). These studies inevitably highlight how epistemologies, ontologies, ethics and politics are entangled in phenomena - and must be grappled with in that dynamic complexity. Hence they show how path dependencies produce lock-ins, but also reveal hopeful monsters, switches, tipping points and alternative futures, allowing 'affirmative critique' at multiple scales.

Complicating matters yet further is the proliferating hybridity in the familiar categories of intersectionality itself - viz. trans- or non-binary gender, mixed race, other species, or the shifting socio-materially mediated definitions of identities such as 'aged' or 'disabled'. The very implacability of the call of 'intersectionality', in other words, resonates with a 'dwelling' in the troubled hubbub of planetary, cosmopolitized system emergence, and promises to stimulate insightful work towards the key challenge of a rethinking of the very concept of the 'human'. As Parent (this issue) brings to light, the very notion of what it is to be human often revolves around an assumption of particular forms of embodiment. Philosophies of thinkingand-walking or mobile methods based on "walking with" presume a bipedal, upright subject of sorts, whereas for many the human condition may involve 'wheeling.' Human capacities to be mobile intersect with the physical materiality of the world in differential ways and may mobilize complex assemblages of transportational and communicative technology. Parent's work demands that we complicate our methodological and epistemological practices to encompass the full range of human (im)mobilities.

Regarding disability, Goggin (this issue) also discusses the potential for a cross-fertilization of critical disability studies and mobilities research to illuminate key issues concerning precisely such questions of digital, post-human lives and inequalities. He draws on the complex intertwined histories (and present) of communicative technologies, especially the mobile phone, cars, homes and cities, and their interaction with shifting definitions of - and enablements and constraints of those with - disabilities, to show how central, and as yet unacknowledged, is the issue of disability to shaping future systems of mobility that are attentive to issues of social justice in the $21^{\text {st }}$ century. Goggin highlights how tacitly 
normative judgements about 'human' movement - e.g. quintessentially as walking - are unsettled when treating disabled movement as of equal value and importance; but also gestures towards a rethinking of the concept of 'human'. Incorporating the disabled human (up to $25 \%$ of humanity, as he notes) into that category is joined by multiple emerging 'posthuman' technologies of mobility and communication for the disabled. Rather than an austere and pitiless trans-human future of machine-based human enhancement, he envisions a technologically-mediated future that may nevertheless deepen enablement of humans, in the irreducible diversity of their capacities and frailties, and hence contributes to a deeper recognition of the 'human', not its transcendence.

Attending to two other key elements of intersectionality, Murray et al. ask [p.] 'how mobilities scholars might be more attentive to gender', age and/or generation and 'the ways in which mobilities and urban space' and their inequalities 'are co-produced'. Their comparative and ethnographic methodology calls for detailed appreciation of the ways in which embodied persons encounter the contested and mobile spaces of streets, highlighting issues of time and space or place, as concrete, relational settings, not abstractions. Regarding time, for instance, the need for longitudinal studies is discussed as key for insights into forms of mobile inequalities, as are the importance of seeing generation as a matter not just of biological age, but of situated and changing relations amongst individuals. Regarding space, understanding intersectional inequalities demands attention to relations within and with particular, concrete places as well as the embodied, multi-sensorial and affective experiences and responses of people. They focus on three place(s) 'in which the pace of mobility is slowed or stopped but in which there is rarely a stillness': three street benches across three cities in three continents. Their study not only highlights multiple experiences of street space, thereby illuminating 'the ways in which people of different generations and gender may be marginalised', but also draws out the challenges and learning needed for intersectional research, including a need for 'telescopic thinking' to look across times and spaces in ways that also then focus in on the concrete lived experience and situatedness of those involved.

Hall and Smith also pick up themes of inequality at street level, focusing on class, care and mobilities. They are concerned with a highly mobile - 'too' mobile - population in cities that is also often made to move and live 'invisibly', especially from the perspective of city centres competing for the global attention: the homeless. Following a team employed by local government to care for the homeless in Cardiff, they highlight first the challenges of mobility inherent to this job, in which their 'clients' are constantly moving and difficult to track down. The homeless for whom this team provide care services are often invisible or 'lost', not just physically difficult to trace but also (generally treated as) socially and biographically confused and broken. The specific mobile practice of this care team, therefore involves not a conventional directed moving towards subjects in need of care but a purposeful but destination-less searching for the 'invisible' traces, tracks and tacit hideouts. This raises broader questions about reconceiving binaries of purposive vs. aimless movement; and thence about reconceptions of the specific forms of urban care this work instantiates and what a 'good city', a city of care for (the im/mobility of) all those it encompasses, could look like.

Regarding issues of (in)visibility and critical race studies, Nicholson argues that the future of mobilities research should consider how the gun, alongside the automobile and the camera, is also a mobile technology of race. She shows how 'a law-and-order gaze is mediated as much by the automobile as by the proximate articulation of camera and police gun' [pg.], whether in the form of a police dashboard camera, bystander phone camera, or police body camera. Drawing together cultural analysis and mobilities research perspectives, Nicholson develops 
the concept of 'gunscapes' as 'a primary lens for interpreting how the gun is used to mediate racial im/mobilities' in the pre-digital and post-digital age, viewed through the articulation of the gun with the camera historically and today. Like Murray et al.'s analysis of the aged and gendered elements of spatial design, or Parent's auto-ethnography of streetscapes that prevent wheeling, Nicholson shows the differential affects of the racialization of space through design, policing, surveillance, and practices of moving through such spaces in diverse ways. Each case shifts our perspective on how, where and when we find intersectionality.

Intersectionality, though, may also cross other scales and forms of being beyond the human or the urban. Combined with a systems perspective and responding to the predicament of the imperative of a qualitatively new concern for the system of planet Earth as a whole, Szerszynski shows not only a new reality of 'planetary mobilities' that must be understood and tended to, but also how these globe-spanning mobilities are utterly dependent on forms of movement and mobility that extend beyond the human social world. An Anthropocenic appreciation of the 'other materialities' of planetary mobilities and issues of inequality, mobility and environmental justice thus calls for new vocabularies and conceptual frameworks that can span and integrate the geophysical and abiotic, the biotic and the living planet (or Gaia?), and the socio-technical or emerging global 'techno-sphere'. This opens up possibilities for a rich and suggestive synthesis of terminologies and typologies between the natural, engineering and social sciences of mobility and system metabolism, including issues of types of motion, patterns of motion and the interaction of mobilities and system dynamics.

Finally, Kanger and Schot take up concerns about reorientation to studies that illuminate life at the 'human' scale in the context of the key issue of understanding socio-technical systems transitions. They trace possible points of productive contact between transitions studies and mobilities and the possible role of research in expediting actual transitions in these complex dynamic, multi-levelled and multi-factorial systems. For urgent as such transitions may be, there remain significant gaps in our understanding of these processes, and of the translatability of historical insights to the unprecedented challenge of their deliberate and real-time cultivation (Smith et al. 2010). Moreover, the challenge here is not merely one of expediting decarbonisation, but also doing so in ways that generate specific qualitative social futures, with specific winners and losers (Stirling 2009). While many of the insights regarding transitions processes to date arise from studies adopting a panoramic and abstract perspective, the roles, contributions and experiences of agents remain relatively neglected. In this situation, the question of how 'users' contribute to and shape transitions (including at the 'landscape' level) becomes key, while also opening up connections with the concern in mobilities research for lived everyday practices and 'mobile lives'.

\section{Conclusion}

In conclusion, emergent from this collection of papers at the 'intersections' of mobilities research with a multitude of other perspectives is a vision not so much of a way out of the crossroads - out of the pervasive 'solutionism' that characterises much of the efforts to address contemporary dystopian dynamics around automation and no-job futures, climate change, political conflict, crisis and surveillance, or out of difficulties of post-disciplinary research - but a set of experiences, epistemological and methodological practices, and orientations that generate creative friction, that enable affirmative critique of both utopian and dystopian dynamics, that create new new insight and make it actionable, that generate methodologies for acting with enhanced sensitivity to ignorance and surprise, desirable and undesirable, intended and unintended consequences, and complex intersectionalities. 
'Dwelling in intersections' produces reflexive and more power-sensitive practices of dialogical intervention in strategic cosmopolitized realities. The 'mobilities' of intersection themselves emerge changed from these encounters. They are situated within persistent, complex and messy human predicaments and efforts of 'dwelling' and 'living together well' not in the sense of eliminating conflict, but as a means of detecting and opening up new spaces and new methodologies for debate and contestation, recognising that one person's utopia can be another's dystopia. Thence the mobile, analytical, inventive, speculative intersections become co-mobilities for a while, encouraging collaborative search for traction.

Transformations of what it means to be human 'in the world' that become tangible in this engagement necessarily evoke questions regarding the place of human knowledge and methodologies of knowing in understanding and 'controlling' mobility pasts, presents and futures. Across the papers are recurring themes of the challenges of methodological innovations needed for mobilities research to grapple with ignorance and surprise and a need for greater phronetic attention to inequalities, domination and power relations. Other common themes include the productive, unpredictable, unplannable, spontaneous effects of new relations, the role of experimentation, speculation, design and broad analytical orientation to movement, rhythm, and intersectionalty and an orientation to uncertain futures, with an extending spatial and temporal gaze alongside greater humility about possibility of certain prognostications.

Dwelling in intersections involves imaginative and collective experiments of, not just charting, but of being (mobile) in other places, times and embodied subjectivities, where both the movement and stillness of learning - as both in formalized research and practical everyday life - come together in a permanently alert searching not for 'solutions' but for active/pro-active and circumspect responsiveness to social challenges and opportunities. The papers in this special issue variably suggest and open up multiple programmes of research with much to learn. In this spirit, instead of conceiving the vistas of new territories they open up as domains of knowledge to master, or as demanding decisions about ways forward, perhaps we can instead develop our capacities to design assembly points conducive for deep engagement where multiple parties can arrive in our various ways, and coordinate moves together to define and shape 'better' worldly, epistemological and methodological futures.

Methods of making moves with greater circumspection and more deeply informed by the various forms of knowledge production found at the intersections of mobilities research, involves moving backwards and sideways, too, to ensure awareness of the longue durée and appreciation of multiple forms of knowledge. It also requires synchronising the rhythms of social science more productively with the rhythms of environmental, societal, cosmopolitan and planetary evolution and socio-technical innovation. This does not necessarily imply a need to speed social science up! Moving methods into acting in the world (Kimbell 2011), can bring knowledge production into the ethical, political and creative momentum of eternal 'worlding' in ways that would enable affirmative or, we prefer, 'experimental' critique through greater, richer, deeper circumspection, and awareness of divisions and inequalities; that is, a form of critique that actively engages in building on research insights to define, shape and practically contest and make 'better' futures. 


\section{Acknowledgements}

\section{References}

Adey, P. 2006. "If mobility is everything then it is nothing: towards a relational politics of (im)mobilities.” Mobilities, 1 (1): 75-94.

Adey, P. 2009. "Facing airport security: affect, biopolitics, and the preemptive securitisation of the mobile body.” Environment and Planning D: Society and Space, 27: 274-295.

Adey, P. 2010. Aerial Life: Spaces, Mobilities, Affects. Malden, MA: Wiley-Blackwell.

Aldred, R., \& Jungnickel, K. (2014). Why culture matters for transport policy: the case of cycling in the UK. Journal of Transport Geography, 34, 78-87.

Amoore, L. 2006. "Biometric Borders: Governing Mobilities in the War on Terror." Political Geography 25 (3): 336-351.

Amoore, L. 2015. "The Work of the Border in the Age of Digital Mobility”. Presentation at the Mobility Intersections Workshop, 6-7 July 2015 at Lancaster University UK.

Abstract available at http://www.lancaster.ac.uk/fass/events/mobilityintersections/index.htm

Anderson, B. 2010. Preemption, precaution, preparedness: Anticipatory action and future geographies. Progress in Human Geography, 34(6), 777-798.

Aradau, C. 2004. The Perverse Politics of Four-Letter Words: Risk and Pity in the Securitisation of Human Trafficking. Millennium - Journal of International Studies, 33(2), 251-277.

Barad, K. 2007. Meeting the Universe Halfway. Durham: Duke University Press.

Beck, U. 2006. The Cosmopolitan Vision. Cambridge: Polity.

Beck, U., and E. Grande. 2010. "Varieties of Second Modernity: The Cosmopolitan Turn in Social and Political Theory and Research." British Journal of Sociology 61 (3): 409-443.

Beck, U., A. Blok, D. Tyfield and J. Y. Zhang 2013. "Cosmopolitan Communities of Climate Risk: Conceptual \& Empirical Suggestions for a New Research Agenda.” Global Networks 13 (1):1-21.

Bettini, G. 2013. "Climate Barbarians at the Gate? A Critique of Apocalyptic Narratives on 'Climate Refugees.”' Geoforum 45: 63-72.

Bonham, J., \& Johnson, M. 2015. Cycling Futures. Adelaide: University of Adelaide Press.

Braidotti, R. 2010. On Putting the Active Back into Activism. New Formations, 68(1), 4257.

Braudel, F. 1982. Civilization and Capitalism 15- $18^{\text {th }}$ Century, Volume 2, The Wheels of Commerce, (trans. S. Reynolds), London: Fontana Press.

Brenner, N. and Schmid, C. 2015. “Towards a new epistemology of the urban?” City, 19 (23): 151-182.

Bruns, A. (2008). Life beyond the public sphere: Towards a networked model for political deliberation. Information Polity, 13(1-2), 71-85.

Burawoy, M. 2005. "For Public Sociology.” American Sociological Review 70(1): 4-28.

Büscher, M. 2006. Vision in Motion. Environment and Planning - Part A, 38(2), 281-299.

Büscher, M., Urry, J., Witchger, K. (Ed.) 2011. Mobile Methods. London: Routledge.

Büscher, M. 2016 (forthcoming). “Moving Methods.” In: Lury, C. (Ed.) International Handbook of Interdisciplinary Methods. London: Routledge.

Büscher, M., Kerasidou, X., Liegl, M., \& Petersen, K. 2016. “Digital Urbanism in Crises.” In R. Kitchin \& S-Y. Perng (Eds.), Code in the City (163-177). London: Routledge.

Chapman, O., \& Sawchuk, K. 2012. "Research-Creation: Intervention, analysis and 'family resemblances’”. Canadian Journal of Communication, 37(1), 5-26. 
Cooper , B. 2016. 'Intersectionality', in Lisa Disch and Mary Hawkesworth (eds), The Oxford Handbook of Feminist Theory, Oxford: Oxford University Press.

Cresswell, T. 2006. On the Move: Mobility in the Modern Western World. New York: Routledge.

Cresswell, T. 2016. "Black Moves: Moments in the History of African-American Masculine Mobilities.” Transfers: International Journal of Mobility Studies 6(1): 12-25.

Cwerner, S.; Kesselring, S. and Urry, J. (eds) (2009). Aeromobilities: Theory and Methods. London and New York: Routledge.

Dennis, K. and Urry, J. 2009. After the Car. Cambridge: Polity.

Ehn, P. 2008. Participation in design things. In PDC '08 Proceedings of the Tenth Anniversary Conference on Participatory Design 2008, Indiana University (pp. 92-101). Indianapolis.

Faulconbridge, J. and A. Hui. 2016. Traces of a Mobile Field: Ten Years of Mobilities Research. Mobilities 11(1): 1-14.

Fincham, D. B., McGuinness, M., \& Murray, L. 2009. Mobile Methodologies. \$: Palgrave Macmillan.

Flyvbjerg, B., T. Landmann and S. Schramm (eds). 2013. Real Social Science. Cambridge: Cambridge University Press.

Freudendal-Pedersen, M. 2009. Mobility in Daily Life: Between Freedom and Unfreedom. Farnham, UK and Burlington, VT: Ashgate.

Furness, Z. 2007. Critical Mass, Urban Space and Vélomobility. Mobilities, 2(2), 299-319.

Galloway, A., Brucker-Cohen, J., Gaye, L., Goodman, E., \& Hill, D. 2004. Design for hackability. In Proceedings of the 2004 conference on Designing interactive systems processes, practices, methods, and techniques - DIS '04 (p. 363). New York, New York, USA: ACM Press.

Galloway, A. 2013. "Emergent Media Technologies, Speculation, Expectation and Human/Nonhuman Relations.” Journal of Broadcasting and Electronic Media, Vol. 57.

Galloway, A. 2015. "Do People Dream of Electric Sheep?: Probing futures through speculative design”. Presentation at the Mobility Intersections Workshop, 6-7 July 2015 at Lancaster University UK. Abstract available at http://www.lancaster.ac.uk/fass/events/mobility-intersections/index.htm

Gaver, B., Dunne, T., and Pacenti, E. 1999. Design: Cultural probes. Interactions, 6(1), 2129.

Geels, F.W. 2002. “Technological Transitions as Evolutionary Reconfiguration Processes: A Multi-Level Perspective and a Case-Study.” Research Policy 31(8-9), 1257-1274.

Geels, F., Kemp, R., Dudley, G. and Lyons, G. (2013) 'Preface', in F. Geels, R. Kemp, G. Dudley and G. Lyons (eds), Automobility in Transition? Abingdon: Routledge

Goggin, G. 2011. Global Mobile Media. New York: Routledge

Gregory, D. (2011). From a View to a Kill: Drones and Late Modern War. Theory, Culture \& Society, 28(7-8), 188-215.

Gross, M. 2010. Ignorance and Surprise. Cambridge (MA): MIT Press.

Hall, T. A. and Smith, R. J. 2015. Care and repair and the politics of urban kindness. Sociology 49(1), pp. 3-18.

Han, S.-J. and Y.-D. Park. 2014. "Another Cosmopolitanism: A Critical Reconstruction of Neo-Confucian Conception of Tianxiaweigong (天下爲公) in the Age of Global Risks.” Development and Society 43(2): 185-206.

Harari, Y.N. 2015. Sapiens: A Brief History of Humanity. London: Vintage.

Haraway, D. 2010. Staying with the Trouble: Xenoecologies of Home for Companions in the Contested Zones. Cultural Anthropology Online. http://www.culanth.org/fieldsights/289- 
staying-with-the-trouble-xenoecologies-of-home-for-companions-in-the-contested-zones [Accessed $1^{\text {st }}$ April 2015]

Hartswood, M., Procter, R., Slack, R., Voss, A., Büscher, M., Rouncefield, M., \& Rouchy, P. 2002. Co-realisation: Towards a principled synthesis of ethnomethodology and participatory design. Scandinavian Journal of Information Systems Vol.14 (No.2). pp. 930.

Housley, W., Procter, R., Edwards, A., Burnap, P., Williams, M., Sloan, L., and Greenhill, A. 2014. Big and broad social data and the sociological imagination: A collaborative response. Big Data \& Society, 1(2): 1-15.

Jensen, O.B. 2013. Staging Mobilities, London: Routledge.

Jensen. O.B. 2014. Designing Mobilities. Aalborg: Aalborg University Press.

Kaplan, C. 1996. Questions of Travel. Durham and London: Duke University Press.

Kaplan, C. 2006. "Mobility and War: The Cosmic View of US 'Air Power'.” Environment and Planning A 38: 395-407

Kimbell, L. (2011). Rethinking Design Thinking: Part I. Design and Culture, 3(3), 285-306.

Laurier, E. 2004. Doing Office Work on the Motorway. Theory, Culture \& Society, 21(4-5), 261-277.

Lury, C., \& Wakeford, N. 2012. Inventive Methods: The Happening of the Social. London: Routledge.

Massey, D. 1994. Space, Place and Gender. Cambridge: Polity.

McDowell, L. 2013. Gender, Identity and Place: Understanding Feminist Geographies. Cambridge: Polity.

Marres, N. 2009. Testing Powers of Engagement: Green Living Experiments, the Ontological Turn and the Undoability of Involvement. European Journal of Social Theory, 12(1), 117-133.

Merriman, P. 2014. Rethinking Mobile Methods. Mobilities, 9(2), 167-187.

Metz, D. 2013. Peak Car and beyond: The Fourth Era of Travel. Transport Reviews 33 (3) (May): 255-270.

Middleton, J. 2010. "Sense and the City: Exploring the Embodied Geographies of Urban Walking.” Social \& Cultural Geography 11(6): 575-596.

More, M. and N. Vita-More (eds). 2013. The Transhumanist Reader. Chichester: WileyBlackwell.

Morozov, E. 2013. To Save Everything, Click Here. London: Penguin.

Nayar, P.K. 2014. Posthumanism. Cambridge: Polity.

Nicholson, J. and Sheller, M. 2016. "Introduction: Race and the Politics of Mobility." Transfers: Interdisciplinary Journal of Mobility Studies, 6 (1).

Owen, R., Macnaghten, P., and Stilgoe, J. 2012. "Responsible Research and Innovation: From Science in Society to Science for Society, with Society”, Science and Public Policy 39(6): 751-760.

Packer, J. 2008. Mobility without Mayhem: Safety, Cars, and Citizenship. Duke University Press.

Palen, L., Vieweg, S., Sutton, J., \& Liu, S. B. 2009. Crisis Informatics : Studying Crisis in a Networked World. Social Science Computer Review, 27(4), 467-480.

Palsson, G., B. Szerszynski, S. Sörlin, J. Marks, B. Avril, C. Crumley, H. Hackmann et al. 2013. "Reconceptualizing the 'Anthropos' in the Anthropocene: Integrating the Social Sciences and Humanities in Global Environmental Change Research." Environmental Science \& Policy 28: 3-13.

Ratto, M., Wylie, S. A., \& Jalbert, K. (2014). Introduction to the Special Forum on Critical Making as Research Program. The Information Society, 30(2), 85-95. 
Sawchuk, K. (2014) 'Impaired', in Adey, P., Bissell, D., Hanman, K., Merriman, P. and Sheller, M. (eds.) The Routledge Handbook of Mobilities. London : Routledge, 570-584.

Sheller, M. 2011. "The Emergence of New Cultures of Mobility: Stability, Openings and Prospects.” In Automobility in Transition?, edited by Frank Geels, René Kemp, Geoff Dudley and Glenn Lyons, 180-201. Abingdon: Routledge.

Sheller, M. 2013. "The Islanding Effect: Post-Disaster Mobility Systems and Humanitarian Logistics in Haiti.” Cultural Geographies, 20 (2): 185-204.

Sheller, M. 2014. “The New Mobilities Paradigm for a Live Sociology.” Current Sociology, 62: 6 (2014): 789-811

Sheller, M. 2015. "Racialized Mobility Transitions in Philadelphia: Urban Sustainability and the Problem of Transport Inequality." City and Society, 27 (1): 70-91.

Sheller, M. 2016a. 'Uneven Mobility Futures: A Foucauldian Approach,' Mobilities, 11 (1): 15-31.

Sheller, M. 2016b. "Connected Mobility in a Disconnected World: Contested Infrastructure in Post-Disaster Contexts.” Annals of the Association of American Geographers, 106 (2): 330-339

Sheller, M., \& Urry, J. 2003. Mobile Transformations of `Public’ and `Private' Life. Theory, Culture \& Society, 20(3), 107-125.

Sheller, M. and Urry, J. 2016. 'Mobilising the New Mobilities Paradigm,' Applied Mobilities 1 (1): I-XX.

Simonsen, J., Bærenholdt, J. O., Büscher, M., \& Scheuer, J. D. (2010). Design research. Synergies from interdisciplinary perspectives. London: Routledge.

Smith, A., J.P. Voß and J. Grin. 2010. "Innovation Studies and Sustainability Transitions: the Allure of the Multi-Level Perspective and its Challenges.” Research Policy 39(4) 435448

Spinney, J. 2016. Fixing mobility in the neoliberal city: cycling policy and practice in London (UK) as a mode of political-economic and bio-political governance. Annals of the Association of American Geographers, 106(2), 450-458

Southern, J. 2012. Comobility: How Proximity and Distance Travel Together in Locative Media. Canadian Journal of Communication, 37(1), 75-91.

Stirling, A. 2009. 2009. Direction, Distribution and Diversity! Pluralising Progress in Innovation, Sustainability and Development, STEPS Working Paper 32, Brighton: STEPS Centre.

Szerszynski, B. 2012. "The End of the End of Nature: The Anthropocene and the Fate of the Human.” Oxford Literary Review 34(2), 165-184.

Thrift, N. 2007. Non-representational theory: space, politics, affect. London: Routledge.

Thrift, N. 2011. Lifeworld Inc-and what to do about it. Environment and Planning D: Society and Space, 29, 5-26.

Tyfield, D. 2014. "Putting the Power in 'Socio-Technical Regimes': E-Mobility Transition in China as Political Process.” Mobilities 9(4): 585-603.

Tyler, I. and Loyd, J. 2015. "In a world of commonplace horrors how do we talk about the refugee crisis?” Accessed at https://www.opendemocracy.net/can-europe-makeit/imogen-tyler-jenna-lloyd/in-world-of-commonplace-horrors-how-do-we-talk-about-ref

Urry, J. 2003. Global Complexity. Cambridge: Polity.

Urry, J. 2011. Climate Change and Society. Cambridge: Polity.

Urry, J. 2013. Societies beyond Oil. London: Zed.

Urry, J. 2014. Offshoring. Cambridge: Polity.

Urry, J. 2016. What is the future? Cambridge: Polity.

Vukov, T. and Sheller, M. 2013. "Border Work: surveillant assemblages, virtual fences, and tactical counter-media.” Social Semiotics 23 (2): 225-241. 
Wilkie, A. Michael, M. (2009) Expectation and Mobilisation: Enacting future users. Science, Technology and Human Values, Vol. 34, No. 4, 502-522. 